\title{
Individuals' rights and wrongs
}

SIR - By chance, I happen to be well acquainted with the three 'case studies' presented by your correspondent Rex Dalton (Nature 383, 107; 1996). I interviewed Timothy Baldwin for a research position in this department a couple of years ago; I was a member of an appointments committee for another post for which Kimon Angelides applied (but was not appointed); and I have known Annmarie Surprenant for many years.

I should like to make two points:

(1) In the case of Baldwin and Angelides, no hint of any possible misbehaviour was contained in the letters of reference received from their previous employers in the United States. It was only through indirect (verbal) contacts with others that I learnt of some of the matters referred to in Dalton's article. I can understand that employers may be chary of committing doubts in writing where no certain evidence exists, but I think the onus is on them to communicate such doubts in some form, perhaps by telephone or e-mail.

(2) The case of Surprenant is quite different: whatever misdemeanour she may have committed in the legal sense, there is no evidence whatsoever that this translates to her scientific research, which has been substantial, significant and reproducible.

Nature should take care to distinguish between scientific misconduct or fraud in the sense of fraudulent or misleading science and social or legal misconduct that happens to be committed by scientists: the two are not the same, and the latter may have no bearing on the veracity of their work.

\section{David Brown}

Department of Pharmacology,

University College London,

Gower Street,

London WC1E 6BT, UK

SIR - With the publication of the News story "International recruitment highlights need to track scientific behaviour", Nature has lowered itself to the level of tabloid journalism. While this may be good for circulation, it does irreparable damage to science and may be harmful to both the health and reputation of individual scientists.

The basic premise underlying this article is incorrect. How many examples are there of scientists who have moved to Europe after inquiries into their activities in the United States? Furthermore, how many of these assumed positions where their new employer was actually unaware of the former difficulties of the scientist in question? In at least two of the three cases cited, the employers knew of the previous difficulties these scientists had encountered, and the scientists are now carrying out their teach- ing and research duties at their new institutions admirably. Why then rehash previous difficulties that they may have had, especially if these issues have still not been completely resolved?

You should understand the personal consequences of the type of character assassination reported in the article. Even if these scientists had made mistakes, is it not conceivable that they have learned from them and are now capable of making substantive contributions to teaching and research?

\section{Jeffrey Rosen}

Department of Cell Biology, Baylor College of Medicine. 1 Baylor Plaza,

Houston, Texas 77030-3498, USA

\section{Blake's heaven}

SIR - I thought it rather ironic that the editors of Nature chose to place William Blake's painting of Newton on the cover of the reprint of the human genetic linkage map article (Nature 380, 152-154; 1996). Blake was a mystic, poet and anti-rationalist who had no tolerance for the ideas arising from the European Enlightenment, upon which the philosophical and scientific foundations of this current work are based. Further, this specific painting reflects Blake's view that Newton, looking down to the ground, absorbed with his protractor and paper, was completely oblivious to the magnificence and splendour within and around him.

Regardless of the intention of the editors, I suspect that Blake's followers would wholly approve of the cover choice - as if a DNA sequence could possibly describe the totality of the human experience.

\section{David L. Bain}

Department of Medicine,

University of Colorado

Health Sciences Center,

4200 E 9th Ave, Box B-151,

Denver, Colorado 80262, USA

\section{Smoke signals}

SIR - I would like to clarify three points raised by Flint ${ }^{1}$ and Britton ${ }^{2}$ in response to my Commentary article on the media handling of preliminary scientific data ${ }^{3}$.

First, I am the genetic toxicologist who is so well known to Oliver Flint and me. I remain grateful for the sample of thalidomide that he gave me in 1984 . The extensive negative mutagenicity data that my colleagues and I have subsequently generated on this chemical have enabled us to classify it with confidence as a nonmutagen, despite the earlier publication of positive muta- genicity data. A preliminary discussion of our data enabled us to counter recent media scare stories regarding the possible germ-cell mutagenicity of this agent to humans ${ }^{4}$.

Second, my comments on butyl benzyl phthalate were neutral and concerned only the way in which preliminary biological data on this chemical were being discussed by the media.

Finally, I evidently trapped myself in the snare of irony when I referred to the assertion that the hazard of passive smoking could be equated to the eating of three hamburgers a day. My use of the word "curiously" was intended to convey my rejection of the analogy drawn. Its bankrupt nature is realized when one attempts to calculate how many hamburgers a day a heavy smoker is implied to have eaten, or when one imagines the consequences to the health of a baby of its being force-fed three hamburgers each day. My views on the advertisement in question are exactly those of Britton ${ }^{2}$.

\section{John Ashby}

Zeneca Central

Toxicology Laboratory,

Alderley Park, Cheshire SK10 4TJ, UK

1. Flint, O. Nature 382, 572 (1996).

2. Britton, J. Nature 382, 572 (1996).

3. Ashby, J. Nature 382, 109 (1996).

4. Ashby, J. \& Tinwell, H. Nature 375, 453 (1995).

\section{Cause and defect}

SIR - You recently published a review of my book The Economic Laws of Scientific Research (Nature 382, 123-124; 1996). More recently, David Swinbanks reported on Singapore's research funding (Nature 383, $110 ; 1996)$, and his report seems to illustrate those laws beautifully.

Between 1978 and 1991, Singapore's expenditure on research and development (R\&D) rose as its gross domestic product (GDP) per capita rose (the first law). In 1991, however, the government set up the National Science and Technology Board with a budget of $\$ \$ 2$ billion, and what happened? After 1992, the rate of growth in the total R\&D budget fell, and that budget has since failed to rise above $1.1 \%$ of GDP. This disappointment is compatible with the displacement of private funding by the government's money (the second law), a displacement that is disproportionate and damaging to the overall $R \& D$ budget (the third law).

The economic laws of scientific research are not an academic conceit. They show how the government funding of research harms the enterprise.

\section{Terence Kealey}

University of Cambridge,

Department of Clinical Biochemistry,

Box 232, Addenbrooke's Hospital,

Cambridge CB2 2QR, UK 